\title{
Mental imagery: pulling the plug on perceptualism
}

\author{
Dan Cavedon-Taylor ${ }^{1}$
}

Accepted: 4 March 2021 / Published online: 28 March 2021

(C) The Author(s) 2021

\begin{abstract}
What is the relationship between perception and mental imagery? I aim to eliminate an answer that I call perceptualism about mental imagery. Strong perceptualism, defended by Bence Nanay, predictive processing theorists, and several others, claims that imagery is a kind of perceptual state. Weak perceptualism, defended by M. G. F. Martin and Matthew Soteriou, claims that mental imagery is a representation of a perceptual state, a view sometimes called The Dependency Thesis. Strong perceptualism is to be rejected since it misclassifies imagery disorders and abnormalities as perceptual disorders and abnormalities. Weak Perceptualism is to be rejected since it gets wrong the aim and accuracy conditions of a whole class of mental imagery-projected mental imagery-and relies on an impoverished concept of perceptual states, ignoring certain of their structural features. Whatever the relationship between perception and imagery, the perceptualist has it wrong.
\end{abstract}

Keywords Aphantasia - Clinical disorders - Mental imagery · Perceptual experience . The dependency thesis - The visual field

\section{Introduction}

Visualise a red door for a few seconds. What kind of psychological state were you just in? Silly question. You were visualising. You were in a visual, or more broadly perceptual, state. The clue was in the name: visualising. Granted, you weren't in a veridical perceptual state; there was, I assume, no actual red door before you. But perceptual states are not always veridical. For one, there are illusions, in which an

Dan Cavedon-Taylor

dan.cavedon-taylor@open.ac.uk

1 Open University, Milton Keynes, UK 
object is seen but its properties mis-seen. More to the point there are hallucinations, in which no object is seen. Mental imagery is just more of the same: a state with sensory phenomenal character that is causally decoupled from the environment. How could imagery not qualify as a perceptual, psychological state?

That was a simple intuition-pump. How might one argue that mental images are perceptual states? Probably one would begin by pointing out some similarities between the two. Let's take stock of the interrelated resemblances that philosophers and psychologists claim to have identified:

- Mental imagery shares with perception an iconic or analog format, with content structured picture-wise, rather than sentence-wise.

- Mental imagery shares with perception content that pertains to sensory properties like colour and shape (in the case of visual mental imagery); timbre, pitch and loudness (in the case of auditory mental imagery); and so on.

- Mental imagery shares with perception nonconceptual content, representing objects and properties in a concept-free way.

- Mental imagery and perception include a point of view in their contents.

- Mental imagery shares phenomenology with perception: what it is like to visualise a red door is fairly close to what it is like to see a red door.

- Mental imagery is always modality-individuated, being visual mental imagery, auditory mental imagery, olfactory mental imagery, and so on. There is no 'modality free' imagery.

- Mental imagery shares neural substrates with perceptual experiences: the visual cortex (in the case of visual mental imagery); the auditory cortex (in the case of auditory mental imagery); and so on.

- Mental imagery systems and processing in the brain can affect perceptual systems and processing in the brain, causing imagery-induced aftereffects of properties like motion and orientation.

- Mental imagery can interact with perception to obscure occurently perceived stimuli (the Perky effect).

- Mental imagery can interact with perception in conditions of binocular rivalry to induce a priming effect similar to that induced by visual perception itself.

- Mental imagery of an object and visual perception of that object engage the same pattern of eye movements, and both require eye movements (saccades) in order to be maintained.

No doubt there are more, but the list is impressive enough. Considered in isolation, any one of these might form the basis of an argument for mental imagery's being a perceptual state; considered cumulatively, the case seems positively overdetermined.

I intend to push back. My aim in this paper is to put pressure on the idea that mental imagery ought to be categorised as a perceptual state (or, more weakly, as a representation of one), a view I will call perceptualism about mental imagery.

I won't be making a positive case for any non-perceptual theory of mental imagery; my project is wholly negative, to eliminate one (really, two) answer(s) to the question 'how are perception and imagery related?' Nevertheless, it might be 
helpful to get a sense of the alternatives. Here are three. First, one might place mental imagery on the side of the cognitive, with belief, desire and the rest. ${ }^{1}$ Second, one might place mental imagery on the side of the merely sensational, with afterimages, pains and so on. ${ }^{2}$ Third, one might claim mental imagery is a sui generis psychological state. ${ }^{3}$

But how might one begin to support any of these alternatives in light of the overwhelming number of resemblances between imagery and perception just listed? One approach would be to divide and conquer, challenging the resemblances one at a time, or perhaps in concert, so that the cumulative case crumbles. Another would be to grant the resemblances, but explain away their significance. I will take a different approach. I will argue that perceptualism is false by providing new arguments against it. I won't address any of the points on the list above list directly. Though for what it is worth I believe that some are open to significant doubt, others simply false, and that some, while true, are insignificant. ${ }^{4}$

My plan is straightforward: In Sect. 2 I distinguish two forms of perceptualism: strong and weak perceptualism. In Sect. 3 I argue against strong perceptualism, drawing upon recent work in clinical psychology to show how it wrongly classifies both imagery-based and psychological disorders as perceptual disorders. In Sect. 4 I argue against weak perceptualism, showing that it gets wrong the aim and accuracy conditions of a significant class of mental imagery — projected mental imagery — and operates with a conception of perceptual experience that is impoverished by its defender's own lights. Section 5 concludes.

\section{Two kinds of perceptualism}

Let's make a distinction. Strong perceptualism says that mental imagery is a perceptual state, belonging to a fundamental psychological kind whose kind-mates include veridical perception, illusion, hallucination, etc. Put otherwise, perceptualism says that states of the imagination are a proper subset of perceptual experience, just as veridical perceptual experiences, illusory perceptual experiences and hallucinatory experiences are. ${ }^{5}$ We shall see in the following section that the

\footnotetext{
1 As John Zeimbekis (2015, p.298) points out, this seems to be the view assumed on both sides of the socalled imagery debate (see, e.g., Pylyshyn 1999, p.347). Compare Jacob Beck (2018, p.319): “There is an intuitive difference between perceptual states... and cognitive states such as judging that justice is fairness or imagining your deceased grandmother.".

2 Eric Lormand's (2006) view comes close to this.

3 As I read them, Peter Langland-Hassan (2015) endorses this view. Strictly speaking, the view defined below as weak perceptualism might be understood along these lines. Ultimately, this won't matter for my purposes.

${ }^{4}$ In particular, it is open to considerable doubt that perception and imagery share overlapping neural substrates (Cavedon-Taylor forthcoming). Experimental psychology may suggest that this is the case. Clinical psychology, however, certainly does not.

5 The idea that these are all subsets of the same type of psychological state, or are instances of a socalled 'fundamental common kind', is controversial. Disjunctivists like Martin (2002) Soteriou (2013) deny it. It is thus no surprise that they deny strong perceptualism, opting instead for weak perceptualism.
} 
view can be developed in a number of different ways. Historically, Hume (1739, 2000), along with Hobbes $(1651,1991)$, is one of the leading defenders of strong perceptualism. Despite claiming that states of the imagination, like mental imagery, and perception differ in "force and liveliness" (1.1.1.1), Hume nonetheless considers them to belong to the same psychological kind:

That idea of red, which we form in the dark, and that impression which strikes our eyes in sun-shine, differ only in degree, not in nature. (1.1.1.5)

Indeed, one might reasonably call the strong perceptualist a 'Humean' about mental imagery (Siegel \& Silins, 2015, p.791).

Weak perceptualism is more guarded. It says that mental imagery is a representation of a perceptual state. Consider the imagery of a red door from a moment ago. Strong perceptualism affirms, but weak perceptualism denies, that you were just in a perceptual state. Weak perceptualism instead says that you were in a state that attempted to approximate, or mimic, or simulate, or recreate etc. a perceptual state. You didn't, just a moment ago, visually experience a red door, on such a view, as a strong perceptualist would claim. Instead, you represented to yourself a visual experience of a red door. Mental imagery, on weak perceptualism, stands to perceptual experience as a portrait of Joshua does to Joshua himself: a different kind of thing, but one that nonetheless bears a conceptual connection to its object by virtue of necessarily standing in a representational relation to it.

Strong and weak perceptualism are not always sufficiently distinguished in the literature, even by their adherents. Thus, I aim to be particularly careful here. For instance, Alvin Goldman signals adherence to weak perceptualism when he claims that "visualizing is, precisely, attempted enactment of seeing." (2006, p.152) Yet on the following successive pages of his discussion he talks in strong perceptualists terms of "equivalence between visual perception and imagery." (p.153) Furthermore, and as Fabian Dorsch points out (2016, p.41-44), it wouldn't take much tinkering with Hume's view to transform it from strong perceptualism into weak perceptualism. Indeed, given Hume's copy principle, it might be more accurate to say that Hume, like Goldman, equivocated between the two views.

If the difference between strong and weak perceptualism still appears only slight, hopefully it won't by the end of this section. For one, weak perceptualists deny that one can imagine objects directly. What mental imagery represents, on weak perceptualism, is not objects per se, but perceptual experiences of objects. This, the weak perceptualist claims, is reflected in imagery's including in its content a point of view from which the imagination takes place, e.g., from above, below, etc. (Martin, 2002, p.407). On strong perceptualism, by contrast, one can imagine objects directly, without having to go via experiences of objects. What I call here 'weak perceptualism' is thus the view that is encapsulated in the so-called Dependency Thesis. Here is how M. G. F. Martin puts it:

To imagine sensorily a $\Phi$ is to imagine experiencing a $\Phi \ldots$ On this view, one kind of phenomenally conscious state, an event of imagining, takes as its object another type of conscious state of mind, a sensory experience. (2002, p.404; see also Peacocke, 1985; Smith, 2006; and Soteriou, 2013) 
This is an endorsement of what I'm calling weak perceptualism, since by "imagine sensorily" and "an event of imagining" Martin means to refer to having mental imagery. Notice that Martin puts the view in terms of one "kind" of state (imagery) representing "another type" of state (perception). This is in line with my claim that weak perceptualism understands mental imagery and perception to be different in kind, while nonetheless exhibiting a conceptual connection (see also Byrne, 2007 n.18).

To further appreciate the daylight between the two views, consider the fact that strong perceptualists and weak perceptualists often fail to be sympathetic to one another's views. Weak perceptualists deny that mental imagery is a perceptual state and therefore attempt to drive a wedge between the two. For instance, Gregory Currie and Ian Ravenscroft (2002 p.102), who appear to be weak perceptualists by virtue of conceptualising imagery as 'recreative' of perceptual experience, distinguish imagery from perceptual experience on the grounds that the former is active while the latter is passive. Conceivably, other weak perceptualists may help themselves to this idea too. ${ }^{6}$

How might this active/passive difference be developed? Contrast going to a friend's house and seeing their red door with your producing visual imagery of a red door. Seeing the red door is something that happens to you. Light reflects off the surface of the door and travels in a straight line to your eye where a retinal image is formed. Transduction then occurs across the retinal nerve and, after perceptual processing, a visual experience of a red door occurs. All this is unwilled by you, and the experience will continue so long as you merely face the door and your eyes are open and saccading. But the generation of the mental image of a red door was not unwilled by you. You conjured it. What's more, the average lifespan of a mental image is just $250 \mathrm{~ms}$ (Kosslyn, 1994), rising to merely a few seconds with active maintenance (Cocude et al., 1997).

So some weak perceptualists attempt to take strong perceptualists to task for failing to recognise a significant difference between perception and imagery in how each relates to the will. From the opposite direction, at least one strong perceptualist has attempted to take weak perceptualists to task for being unable to explain behavioural equivalences between seeing $\mathrm{O}$ and having mental imagery of $\mathrm{O}$. Bence Nanay (2015, p.1732), for instance, claims that The Dependency Thesis cannot explain why seeing $\mathrm{O}$ and having imagery of $\mathrm{O}$ trigger identical eye-movements (see Laeng et al., 2014). After all, The Dependency Thesis says that perceptual experiences of Os and mental imagery of Os differ in their contents and are fundamentally different kinds of states; the latter is a representation of a perceptual experience of $\mathrm{O}$ and the former is a representation of $\mathrm{O}$ (or else is acquaintance with

\footnotetext{
6 Currie and Ravenscroft (2002)'s view is complicated by the fact that they nonetheless deny The Dependency Thesis. They hold that having imagery involves representing perceptual experiences, but in such a way that perceptual experiences are not part of the imagery's content (pp.11-12). I am not sure that this is a happy mix of claims. Either way, the objection to weak perceptualism developed in 4.2 will target any view on which it is said that to have imagery is to represent (or mimic, or recreate, or enact, or simulate, etc.) a perceptual experience, whether or not that view also affirms The Dependency Thesis, as I suspect coherence requires.
} 
$\mathrm{O}$, in the case of naïve realists). Nanay claims that this result is puzzling for defenders of The Dependency Thesis since, for them, imagery is not "structurally similar" to visual experience. (p.1732).

Given the depth of disagreement between the two views, is it a mistake to lump them together? Certainly not. Both agree that perceptual experience is the key to unlocking the mysteries of mental imagery. Strong and weak perceptualism, for all their disagreement, agree crucially on this: mental imagery cannot be understood apart from perception. Where they differ is merely over the sort of conceptual connection imagery is said to bear to perception: whether 'imagery' names a type of psychological state that is a proper subset of perceptual experience (strong perceptualism) or else names a type of state that necessarily represents perceptual experience (weak perceptualism). It is important not to lose sight of this point of connection between the two views, despite their differences. Like strong perceptualists, weak perceptualists believe that mental imagery can be understood only through the 'lens' of perception. ${ }^{7}$

\section{Against strong perceptualism}

Strong perceptualism says that mental imagery is a proper subset of perceptual experience, just as veridical, illusory and hallucinatory experiences are. In this section I argue against strong perceptualism on the basis that it wrongly classifies imagery-related disorders and abnormalities as perceptual disorders and abnormalities, when at least some of these seem best characterised as cognitive disorders. Many contemporary strong perceptualists claim that their view is empirically supported. I shall show that they are wrong on this score. First, however, a word or two more on strong perceptualism itself.

\subsection{More on Strong Perceptualism}

In addition to Hobbes and Hume, strong perceptualism has, much more recently, been defended by Bence Nanay (2010, 2015, 2016, 2017, 2018, 2020, 2021 and forthcoming). Nanay will be my chief stalking horse through this section, though the objections I give target any version of the view. Other strong perceptualists include, by my lights, Alex Byrne (2007, p.135), who claims that (visual) mental imagery involves representations "proprietary to the sense of sight" and which, like veridical, illusory and hallucinatory states, involve "the appearance of actuality." (p.134) Compare also Nick Wiltsher (2016), who claims that we can use theories of perceptual content, like Peacocke's (1992) scenario and proto-propositional theory, to develop theories of imagery content. Strong perceptualism also figures in the predictive processing theory of perception. Andy Clark claims that to be a perceiver

\footnotetext{
7 I discuss non-perceptual accounts of imagery at greater length in Cavedon-Taylor (forthcoming).
} 
is to deploy the same internal states as those deployed in imagery, with there being a "deep unity between perceiving and imagining" (see also Hohwy, 2013, p.137). ${ }^{8}$

Now, in Nanay's hands, strong perceptualism is sometimes a thesis about personal-level mental states and other times a thesis about sub-personal perceptual processing. For instance, when Nanay (2015) argues against The Dependency Thesis that mental imagery and perception have identical contents and, distinctly, that attention plays an identical role in imagery as in ordinary perception, i.e. tries to make content more determinate, he is conceiving of imagery as a mental state. Similarly, when Nanay (2010) argues that amodal completion, the representation of occluded parts of objects, occurs via one's having projected mental imagery of those parts, e.g., parts of a cat behind a picket fence which do not stimulate one's retina, he is also thinking about imagery as a mental state.

More recently, however, Nanay has shifted to framing his thesis as one concerning perceptual processing, though he takes this to be an "extension" (2018, p.128) of the more ordinary concept of 'imagery', meaning 'mental state'. ${ }^{9}$ But if strong perceptualism as a thesis about mental states is the claim that mental imagery is a subset of perceptual experience, then what is strong perceptualism as a thesis about perceptual processing? Here are two representative statements:

Mental imagery, according to this paradigm, is perceptual processing that is not triggered by corresponding sensory stimulation in a given sense modality. (2018, p.127)

I will use the concept of mental imagery as a technical concept in this paper and use the term 'mental imagery' as a shorthand for 'perceptual processing that is not triggered by corresponding sensory stimulation in the relevant sense modality'. (2020, p.83)

So Nanay no longer intends to capture our everyday concept with the term "mental imagery' but "what psychologists and neuroscientists mean." (2017, p.468) This will be important for my purposes. (It makes the objections all the more difficult for Nanay for handle, since these are based on results from psychology and neuroscience.) Either way, the objections that I give will target strong perceptualism couched either in terms of mental states or else perceptual processing in the brain. Also, it should be clear that, as a thesis about brain processing, Nanay's thesis certainly embodies the spirit of strong perceptualism: mental imagery, he claims, is a kind of perceptual processing.

Finally, although perceptualism is typically developed as a theory of mental imagery involving visual qualities, and indeed vision alone will be my concern here,

\footnotetext{
${ }^{8}$ Kirchhoff (2018) discusses at length the relationship between perception and imagery posited by predictive processing theorists.

9 Nanay scholars, take note: once can witness the sands shifting in Nanay (2016), where he at once defines mental imagery in perceptual processing terms (p.67-68) but still discusses mental images as "mental states" (p.69), particularly in relation to the representationalism vs naïve realism debate (p.77), which is not a debate about brain processing but mental states. There is no mention of perceptual processing at all in Nanay (2015). By Nanay (2017) the shift to discussing mental imagery solely in processing terms is fully complete.
} 
it can be extended to other forms of imagery. For instance, Benjamin Young (2020) has recently extended Nanay's strong perceptualism to olfaction.

\subsection{The Argument from Aphantasia}

Aphantasia is an imagery disorder that can occur both congenitally and following brain damage. ${ }^{10}$ Those with the condition are standardly claimed not to have mental imagery. Experimental and clinical research on aphantasia, while currently blossoming, remain in their infancy. Hence, some caution is needed in characterising the condition. It might be that what aphantasics lack is merely the capacity to self-generate mental imagery. More controversially, it has been suggested that aphantasics have imagery, and merely lack introspective access to that imagery. ${ }^{11}$ Furthermore, many puzzles exist concerning the condition's relation to memory, dreaming, creativity, etc. (Dawes et al., 2020; Zeman et al., 2020; see also Whiteley forthcoming). These controversies won't matter for my purposes.

Suppose that a person acquires aphantasia following brain damage, thereby losing the capacity for mental imagery (or for self-generating imagery, etc.). If strong perceptualism is true, then this person ipso facto loses the ability to have certain perceptual states. They come to have an attenuated quantity of perceptual experiences. Aphantasia is an imagery disorder. Strong perceptualism, in claiming that imagery is a perceptual state, thus classifies the disorder as a perceptual one. Having aphantasia, on strong perceptualism, means being perceptually lacking, to at least some extent. ${ }^{12}$

Yet aphantasia is not a perceptual disorder. Learning that someone has acquired aphantasia, it certainly does not follow that they ipso facto have a perceptual disorder. That is a further, open, empirical matter. Strong perceptualism, as a thesis about imagery qua mental state, is forced to say otherwise. Not only is that an affront to common sense, but psychologists studying aphantasia don't agree either. This suggests that strong perceptualism is also false as a thesis about perceptual processing/what psychologists and neuroscientists mean by 'imagery.' We can appreciate this most clearly by focussing on two concrete cases.

First, consider the patient reported on by Moro et al. (2008). Following head trauma, the patient acquired aphantasia and then struggled with basic, everyday decision-making tasks. Reporting to clinicians on their difficulties ordering a snack, they stated: "When they ask me if I want some crisps or peanuts, I'm unable to answer because I can't mentally distinguish their different shapes." (p.110).

Is the patient's remark evidence of a perceptual disorder? That seems a stretch. Their difficulty seems most aptly characterised as related to practical reasoning

\footnotetext{
${ }^{10}$ Congenitally, aphantasia has been estimated to occur in $2 \%$ of the population (Zeman et al., 2015).

11 This possibility seems recently to have been empirically discredited, on the basis that aphantasics show no evidence of priming by mental imagery in conditions of binocular rivalry (Keogh \& J.Pearson 2018), an effect that is introspection-independent; but then see Nanay (2021). Other objective tests for aphantasia, i.e. which do not rely on first-person reports, are discussed in Zeman et al. (2020, p.427).

12 This is consistent with paradigmatically perceptual, bottom-up processes remaining intact. Thanks to an anonymous referee for pressing me to clarify these matters.
} 
capacities, or to memory, to cognition. Through being unable to generate mental imagery, i.e. of the relevant snacks, the patient was unable to reflect fully on the choices available to them and was thereby unable to form a belief about what to order. Nothing need be amiss perceptually. ${ }^{13}$ Indeed, Moro and their collaborators went so far as to claim that the case illustrates "a very clear dissociation" (Ibid.) between perception and imagery. This is about as strong a denial of strong perceptualism as one can get, whether operating with the common or the technical concept of 'imagery,' and from those Nanay claims are on his side.

Second, consider the aphantasic patient, R.M., reported on by Farah et al. (1988) Through losing mental imagery, R.M. was unable to reliably judge for themselves the truth-value of so-called Eddy and Glass sentences. (Eddy \& Glass, 1981) These are sentences that are thought to require visual imagery for their verification, e.g., "A grapefruit is larger than an orange," and which contrast with sentences that do not, e.g., "Animals are stuffed by a taxidermist." R.M. was found to make numerous errors when undertaking an Eddy and Glass sentence verification test, yet performed "nearly perfectly" when stating the truth-values of the non-imagery sentences. (p.153).

Again, this result goes against strong perceptualism insofar there seems no evidence here of a perceptual disorder. On the contrary, being unable to judge the truth-value of the sentence "A grapefruit is larger than an orange" is a cognitive deficit, not a perceptual one. For the patient's difficulty, in failing to grasp the truthvalue of the relevant Eddy and Glass sentence, was in representing to themselves a certain relational fact about grapefruits as a type, and this is a cognitive difficulty by normal standards. By contrast, R.M. had no difficulty seeing (and presumably hallucinating) particular grapefruits, and their visual object-recognition abilities were reportedly "good." (p.161) Granted, Farah and colleagues observed that the patient's perceptual abilities were not entirely normal. (p.163) Crucially, however, the basis for this judgement was not the imagery disorder, but the patient's verbal alexia; that is, their inability to read whole words, and from which an attentional deficit was inferred.

Now, Nanay is right that there are psychologists and neuroscientists who describe imagery along such lines as 'perceptual processing that is not triggered by corresponding sensory stimulation in a given sense modality.' He provides several examples (2016, p.67). ${ }^{14}$ Many philosophers embrace this way of talking too. Indeed, consider the following remarks from the Stanford Encyclopedia of Philosophy's entry 'Imagination' (Liao \& Gendler 2019): “To have a (merely) mental image is to have a perception-like experience triggered by something other than the appropriate external stimulus."

But the examples of Moro et al. (2008) and Farah et al. (1988) show that this way of describing imagery is not universal among empirical researchers. And it is worth stressing that the patients described by Moro et al. (2008) and Farah et al. (1988) are

\footnotetext{
${ }^{13}$ Indeed, the clinicians further reported that the patient "showed no apparent impairments in their visual perceptual abilities." (Moro et al. 2008, p.112).

14 They are Kosslyn et al. (1995, p.1335); Shepard (1978, p.130); and J. Pearson et al. (2015, p.590).
} 
not isolated cases involving imagery/perception dissociations. Moving away from aphantasia proper, imagery/perception dissociations have been observed to occur at a relatively fine-grain, e.g., for colour, identifying shapes, etc. One clinical review even states that "every type of dissociation is possible" between perception and imagery. (Bartolomeo, 2002, p.372).

Moreover, it is not obvious that Nanay is correct to claim that psychologists talk about imagery primarily in processing terms. For instance, psychologists Chaz Firestone and Brian Scholl (2016), in their recent discussion of cognitive penetration, distinguish perception from imagery partly on grounds of vivacity; this cannot be a claim about processing, but can only be understood as a claim about imagery qua mental state. Moreover, Kosslyn and his collaborators (1995), whom Nanay approvingly quotes as conceptualising imagery in processing terms, in fact introduce imagery in personal-level, mental state terms:

To get a sense for the subject matter, answer the following questions: How many windows are there in your living room? What socks did you wear yesterday? Is there room in your refrigerator for a litre of milk? These questions typically evoke visual mental imagery. (p.1335)

More problematically for Nanay, Kosslyn and his colleagues elsewhere (2006) make remarks that are an outright denial of imagery's being perceptual processing not triggered by corresponding sensory stimulation in a given sense modality. For instance, in light of clinical evidence similar to the above, Kosslyn explicitly cautions against affirming that imagery "is simply perception in the absence of immediate stimuli" claiming that "the two systems are only partially overlapping." (pp.151-2).

In sum: strong perceptualism wrong characterises aphantasia as necessarily a perceptual deficit, when at least some of those with the condition exhibit cognitive deficits and not perceptual ones.

\subsection{The Argument from Psychological Disorders}

A second argument against perceptualism stems from reflection on the discovery of imagery abnormalities in a wide range of psychological disorders, including: posttraumatic stress disorder (PTSD), social phobia, schizophrenia, bipolar disorder and depression.

For instance, intrusive, imagery-based 'flashbacks' are a "hallmark symptom" of PTSD (D.Pearson et al., 2013, p.8), and so might be considered partially constitutive of the disorder. In the case of social anxiety, negatively-valenced third-person imagery, i.e. from the point of view of an interlocutor, is thought to be a maintaining cause of the disorder (Hirsch et al., 2003). The relationship between imagery and schizophrenia is highly complex. A high score on tests for vivacity of imagery is considered a trait marker of the disorder (Oertel et al., 2009), yet schizophrenic subjects typically perform worse than controls on tests that measure the abilities to inspect (Aleman et al., 2005) and maintain (Kang et al., 2011) mental imagery. Imagery's roles in bipolar disorder are likewise knotted. Bipolar subjects typically score high on several imagery measures, including tests for spontaneous use of 
mental imagery (McGill \& Moulds, 2014), e.g., when planning the order of chores, thinking of a friend, or listening to a play on the radio. Moreover, a leading theory in the clinical literature is that intrusive, future-directed mental imagery acts as an 'emotional amplifier' in the condition, modulating mood in the direction of manic highs (Holmes et al., 2008). Finally, in severe depression, subjects are impaired in their ability to generate mental imagery of the future (Williams et al., 1996) yet may experience 'flash-forwards' to their suicide when at their most hopeless (Crane et al., 2012).

Whether imagery abnormalities are causes, effects, constituents or concomitants of psychological disorders must be settled on a condition-to-condition basis. Here's the crucial matter: if perceptualism is true, then each of the above conditions, by virtue of involving imagery abnormalities, ipso facto involves perceptual abnormalities, either as a constituent of the condition (e.g., as in PTSD), a cause of the condition (e.g., as in social phobia), or as an effect or concomitant (e.g., the suicidal imagery sometimes triggered by severe depression).

Again, this is not the right outcome. For whether or not any of the above conditions involve perceptual abnormalities is a further matter, not settled by the fact that they involve imagery abnormalities. This is a result that goes directly against strong perceptualism. Consider bipolar disorder. When Holmes and their collaborators suggest that certain imagery abnormalities are a "defining feature" (2008, p.1254) of bipolar disorder, and Ivins and their colleagues state that such abnormalities "represent a distinctive hallmark" (Ivins et al., 2014, p.240) of the condition, neither is claiming, and nor would this justify anyone claiming, that bipolar disorder is a perceptual disorder. Simultanagnosia, optic ataxia, and oculomotor apraxia are perceptual disorders. ${ }^{15}$ Bipolar disorder is not, whether operating with the ordinary concept and meaning 'mental state' or a technical concept and meaning 'perceptual processing'. Strong perceptualism is again shown here to be in the wrong, whether construed as a thesis about mental states or perceptual processing.

In sum: strong perceptualism wrongly characterises various psychological disorders as necessarily perceptual disorders.

Tellingly, Nanay (2021) has recently claimed that it is a virtue of his processingbased definition of imagery that is sufficiently broad to unify several phenomena: 'filling in' the blind spot, peripheral vision, amodal completion, some illusions and hallucinations, to name only a few. The overall objection developed in this section is that it is, in fact, far too broad. For it will also factor in some practical reasoning deficits (inability to fully reflect on, and choose between, options), certain beliefformation deficits (inability to grasp the truth-value of certain sentences) and some psychological disorders, like bipolar disorder. These all show no signs of being interestingly related to perception or perceptual processing, but are interestingly related to imagery. So one should refrain from being a strong perceptualist. One

\footnotetext{
15 Simultanagnosia is the inability to visually attend to more than one object at the same time. Optic ataxia is a deficit of visual guidance, involving the inability to grasp seen objects. Oculomotor apraxia is the inability to control one's eye movements.
} 
should not characterise mental imagery as a kind of perceptual experience or perceptual processing.

\section{Against weak perceptualism}

Strong perceptualism says that mental imagery is a subset of perceptual experience or perceptual processing. That view is to be rejected on conceptual and empirical grounds. Weak perceptualism claims that mental imagery is a representation of a perceptual experience. Now, certainly a state of kind $K$ may be represented by another state of kind $K$. But a more natural way to understand the view, and indeed how it is pictured by both its defenders (Martin, 2002, p.404) and detractors (Byrne, 2007, n.18), is as claiming that imagination and perception are members of importantly distinct psychological kinds. After all, there is typically a significant difference in kind between a representation of a $K$ and a $K$ itself. A painting of a hundred-dollar bill is not itself legal tender, no matter how realistic, and a drawing of a kitten is neither feline nor fluffy. So weak and strong perceptualism differ. Still, as discussed in Sect. 2, they both agree on a conceptual connection between perception and imagery, they simply differ on the nature of that connection.

In this section I argue against weak perceptualism on the basis that (i) weak perceptualism gives the wrong account of the aim and accuracy conditions of a whole class of imagery, projected mental imagery, and (ii) The Dependency Thesis operates with an impoverished concept of perceptual experiences, ignoring certain of their structural features. First, some more on weak perceptualism.

\subsection{More on Weak Perceptualism}

Weak perceptualists deny that imagery is a perceptual state, and so need to distinguish the two. We saw earlier that Currie and Ravenscroft do so on passive/ active grounds.

This matter must be handled with some care. Mental imagery can sometimes occur all too passively. It can be perception, by contrast, that requires exertion. For instance, clinical psychology has identified unbidden mental imagery in episodes of intrusive thought, addiction and PTSD (Andrade et al., 2012; D. Pearson 2013). In more everyday scenarios, we can also consider flashbacks and 'earworms' (Nanay, 2016, p.66). On the side of perception, cases of effortful perception include, e.g., visually switching aspect on the Necker cube; listening out for a noise; sniffing to tell if that stink has gone yet; and the exploratory actions that are partially constitutive of haptic/exploratory touch. It thus seems we can upend entirely the passive/active contrast commonly claimed to hold between perception and imagery.

Possibly because of considerations such as the above, Matthew Soteriou, a weak perceptualist by virtue of defending The Dependency Thesis, draws the perception/ imagery distinction differently. While still insisting that the difference between the two is in relation to the will, Soteriou argues for a receptive/non-receptive difference rather than a passive/active one. Just as Nanay was the stalking horse for 
strong perceptualism, Soteriou will be the stalking horse for weak perceptualism. His remarks are thus worth quoting at length:

The fact that the temporal location of one's perceptual experience seems to one to be determined by the temporal location of its object is connected with a distinctive respect in which perceptual experience is receptive, and not subject to the will. Even when successful perception involves agential perceptual activity, such as looking, watching etc., one's successful perception depends upon the occurrence of perceptual experience whose inception and course is determined by the temporal location of the object perceived. One might regard cases of so-called 'unbidden' mental imagery, for example a case in which the perceptual recollection of some past event pops up in one's mind unbidden, as passive mental events of which one is not an agent. But even such cases are not truly 'receptive' in the way that conscious sensory experience is. (2013, p.157)

Soteriou's idea is that perceptual experiences, successful ones at least, are guided and shaped by their objects in such a way that the two are experienced as temporally coincident. Mental imagery, by contrast, is not guided and shaped by its objects. Even when there is a causal chain linking the two, as in episodic recall, imagery and its objects are not experienced as temporally coincident. Successful perceptual experiences, by contrast, are 'temporally transparent' to their objects.

\subsection{The Argument from Imagery's Aim}

Weak perceptualism says that mental imagery is a representation of a perceptual experience. An account of the aim of imagery, its relation to truth and accuracy conditions, falls out of this claim:

When a subject perceptually imagines a $\Phi$, a phenomenally conscious episode occurs. Unlike the case of conscious sensory experience, the state that obtains when such an episode occurs is not a perceptual state that is intentionally directed on the subject's environment, but rather a mental state that aims at truth and that represents the phenomenal character of an experience of a $\Phi$. (Soteriou, 2013, p.164)

Perception, on Soteriou's naïve realist account (also Martin's), is a phenomenally conscious relation of awareness to objects in one's environment. Since imagery is, for Soteriou, a representation of perception, it therefore aims at representing a phenomenally conscious relation of awareness; it tries to get right "the phenomenal character of the perceptual experience one would be having if one were perceptually aware of the entity one is perceptually imagining." (p.166).

Soteriou's idea might be put in terms of the direction of fit of imagery and its accuracy conditions being an intra-mental affair: imagery aims to faithfully represent possible perceptual experiences rather than ordinary objects in the external world. This is not a quirk of his view. It is straightforwardly entailed by the weak perceptualist's thinking about imagery as a representation of another psychological (specifically, perceptual) state. So although I focus discussion here on Soteriou, they 
merely make explicit what is implicit in weak perceptualism: that mental imagery has an aim, which is to be accurate to the experience one would have if one were seeing the object represented by one's imagery.

Yet in saying as much, weak perceptualism gets wrong the aim and accuracy conditions of an entire class of mental imagery: projected mental imagery. This is imagery that, contra Soteriou and weak perceptualism, precisely is "intentionally directed on the subject's environment" rather than a possible perceptual experience. Here is an example to help focus discussion.

\section{Headlights in the Dark}

You are driving late at night along a narrow road. Visibility is drastically reduced. Suddenly, a car appears on the road. At least, you assume it to be one; all you can make out are two headlights. To work out whether there is space for the two cars to pass one another, you must make an educated guess as to the size of the other car, given the position of the headlights. But you need to do so in such a way that can directly guide your action. Solution: you imaginatively project, out into the pitch black, the outline shape of a car, around the headlights, that strikes you as being the correct size of the actual car's outline shape.

In the above example, the image is accurate if it roughly matches the size and shape of the actual car and is inaccurate otherwise. The image aims to accurately represent an environmental object, the car, and not another psychological state.

Cases of projected mental imagery abound. Consider projected mental rotation, as when playing Tetris; deciding how to arrange furniture in an empty room or flowers in a vase; navigating a path through a busy train station; telling whether a piano will fit through a doorway; and so on. Projecting mental imagery into one's perceptual experience is one of the strategies we have to help solve these, and related, problems. ${ }^{16}$ Strikingly, this way of tokening imagery has proven highly amenable to empirical investigation, showing itself to be a "real, reliable, and replicable" occurrence (Segal, 1972, p.226; see also Brockmole et al.. 2002, Gosselin \& Schyns, 2003, and Keogh \& J.Pearson 2018). Do not consider such cases to be fringe, as Martin (2002, p.410) and Soteriou (2013, p.160) seemingly do in attempting to pass-off projected mental imagery as a "non-simple" way of tokening imagery.

What should the weak perceptualist say in reply? The best that they can do, I think, is dig their heels in. About Headlights in the Dark, they may say: by projecting the outline of the car into one's perceptual experience one represents a distinct perceptual experience in which the outline of the car is, in fact, seen.

This reply is both coherent and true to the spirit of weak perceptualism. Yet it is hardly an intuitive gloss on the situation. First, the point of projecting imagery in Headlights in the Dark is to correctly represent the actual outline of the car before one, to ensure one doesn't drive into that. What would be the point of recreating a

\footnotetext{
${ }^{16}$ For further discussion and examples of projected imagery, or what is sometimes called 'makeperceive' (Briscoe 2008), see Sellars (1978); Grush (2004); Thomas (2009); Nanay (2010); Van Leeuwen (2011); Macpherson (2012); Zeimbekis (2015); Brown (2018); and Kind (2018).
} 
possible scenario, i.e. how the car would look were you to see it? Your purpose is to handle the actual situation before you.

Second, success or failure in projecting the image is measured against the extramental facts of the situation, rather than any psychological ones. You imagine wrongly if the shape you project is not true to the actual environmental facts, since the projected image is accurate just in case the car is (roughly) the projected shape and size. Crucially, the mental image projected is rationally revisable in light of further information that you receive about the car's shape and size as you approach it. While receiving further information about the visible properties of the car does enable you to better represent how the car would look were you to see it, representing how the car would look is not your aim to begin with, and so the reply misses the larger point: extra-mental facts about the car itself, not facts pertaining to possible perceptual experiences, are what matter for the image's function and accuracy conditions.

In sum: weak perceptualism gives the wrong account of the aim and accuracy conditions of projected mental imagery.

\subsection{The Argument from the Visual Field}

Weak perceptualism and The Dependency Thesis fail as an account of projected mental imagery. They therefore fail in full generality. Might they nonetheless be true as accounts of non-projected imagery, i.e. imagery tokened in the mind's eye? No, and by Martin's and Soteriou's own lights. For ease, I shall focus my discussion on vision.

Vision is not simply about experiencing sensory properties, like colour, shape, etc. and concrete particulars, like chairs, people, trees, etc. Rather, vision is marked by a certain phenomenal feature: a field-like structure. This field-like structure is understood in the literature to be comprised of two sub-features, which I will label intra-visual and extra-visual.

\section{The Two Fold Phenomenology of the Visual Field}

Intra-visual feature: when seeing the scene before one, regions of space inside of that scene are experienced as potential locations for visible objects.

Extra-visual feature: when seeing the scene before one, regions of space at the immediate edges of that scene are experienced as potential locations for visible objects.

The Twofold Phenomenology of the Visual Field is typically described as an invariant or structural feature of vision. The idea is this: although the objects of vision and the properties seen may change from one moment to the next, these features do not. They are present in all visual experiences, and so are independent of what objects and properties are experienced. The Twofold Phenomenology of the Visual Field is thus not among the things we perceive, but belong to the "how" of vision's experiencing those things. (Richardson, 2014, p.493).

The intra-visual feature is the more straightforward to explain: seeing is not merely about experiencing things arrayed in space, but is also about experiencing the space within the array as well. How does one experience this space, 
phenomenologically? As locations at which objects are currently not seen, but would be, were they there.

The extra-visual feature is more nuanced and shall be my concern: seeing is not merely about experiencing things arrayed in space and the space within the array as well; seeing is also about experiencing the scene before one as a sub-region of a larger of region of space that extends beyond the reach of sight. In seeing any scene before one, that scene is experienced as a limited portion of a wider, visual world that one does not currently see. Put simply: the world does not appear to end at the edges of vision. It looks to extend beyond them. ${ }^{17}$

The Twofold Phenomenology of the Visual Field has been put to a number of explanatory uses, including: how one is able to see empty space (Richardson, 2010); as what is missing in Bálint's syndrome (French, 2018); and as requiring us to temper claims about transparency for spatial, but not temporal perception (Hoerl, 2018).

Now, as mentioned above, defenders of The Dependency Thesis are impressed by the idea that both vision and mental imagery involve a point of view from which scenes are seen/imagined, using this fact to motivate their theory. That point of view is also a structural feature of vision: no matter the objects or properties experienced, those objects or properties, in being experienced as external to one, are seen as spatially related to one's body, i.e. to the left, up above, etc. (Martin, 2002, p.407) The point being made here is that there is significantly more structure to vision than this. There is also the Twofold Phenomenology of the Visual Field. Visual experience characteristically involves an experience of space, within which the objects of vision are located (intra-visual feature) and all visual experience involves a sense of one's visual limitations, i.e. that there is more of the visible world always just out of sight (extra-visual feature). As Christoph Hoerl, in acknowledging such features, puts it, "The way visuo-spatial experience is spatially viewpointed... cannot simply be captured by talking about the spatial relationships that are being represented in the experience." (2018, p.144) Here Hoerl precisely means to pick out the features that impress weak perceptualists, being, e.g., to the left, up above, etc. Thinking that these exhaustively characterise the spatial structure of vision is incorrect.

So now recall: Soteriou claims that imagery tries to get right "the phenomenal character of the perceptual experience one would be having if one were perceptually aware of the entity one is perceptually imagining." (p.166) For this to be the case, i.e. for The Dependency Thesis to be true, the intra- and extra-visual features of the visual field must be represented in imagery. Unless they are, imagery will come out on the weak perceptualist's account as, at best, necessarily inaccurate; at worst, the

\footnotetext{
17 Quite how this is possible is a puzzle, one fairly similar to the puzzle of how objects within the visual field are able to look 3-D, given one can't see all their sides at once, i.e. the puzzle of perceptual presence. A possible solution is that the world looks to extend beyond the edges of vision due to one's sensorimotor expectations, i.e. that moving one's eyes, head, etc. will enable one to see more of the visible world. (Cavedon-Taylor 2018).
} 
absence of such features will entail that weak perceptualists lose their right to say that imagery represents visual experiences in the first place. Either way, weak perceptualism will be in significant trouble. In particular, a key motivation for the view, that structural features of perception are reproduced in imagery, will be undercut. So are the two features in question represented? Let us take them in turn.

Does the intra-visual feature figure in the content of visual mental imagery? Plausibly, yes. In visualising the red door, one may experience space within the imagined scene, e.g., as potential locations for other objects of imagination: a wreath, a doorknocker, etc. In visualising a large empty room, I not only experience imagined white walls, from a particular point of view (low down/up high, etc.), I also experience the space within the room to be a potential location for other imagined objects: a couch, a desk, a table, a television, my family, etc. More straightforwardly, in imagining these objects I imagine them as being located within a space that other imagined objects may inhabit. Thus, the intra-visual feature of vision does seem represented by imagery. Needless to say, if I am wrong about this, then so much the worse for The Dependency Thesis.

Crucially, however, the extra-visual feature need not be reproduced. In visualising the red door, I need not have a phenomenal sense of any imagined space outside of that imagined scene, at least not in the relevant manner: a sense of an imagined world that extends beyond the limits of the imagined scene. The imagery of the red door may be replete with detail about, e.g., the door's specular highlights, its height, maybe some surrounding brickwork, etc. Still, for all the image content 'says', the imagined world may well end at the edges of the imagined scene. Imagery content may be, but isn't characteristically, committal about the existence of a wider imaginary world of which the imagined scene is a mere sub-region; not, at least, in the way that visual experience characteristically is.

What is true is that one can continue to populate the edges of the imagined scene voluntarily, so as to build up the image to represent the whole façade of a house. But this is not relevant. The relevant extra-visual analogue that would have to be true in order for the feature to be represented is this: that when the imagined scene is considered at any one instant, e.g., as a door at one moment or later as a façade, one constantly experiences, quite involuntarily, there to be more of the imagined world just out of imagined sight, just as one always experiences, quite involuntarily, there to be more of the visible world just out of actual sight (and which one might turn one's head to see). By contrast, imagined scenes are typically experienced either as self-contained spaces that are not sub-regions of a wider imaginary world, or else imagery simply doesn't comment either way on the scene's being a part of a larger sub-region of an imagined world. In seeing any scene, I experience myself to be visually limited through having a phenomenal, visual sense of there being things outside of the scene that I cannot now see. But in imagining a scene, I do not necessarily experience myself to limited imaginatively in anything like the same manner. I may do, of course. But the point is that this seems to be the exception and not the norm, as in visual perception. 
In sum: weak perceptualism risks making all imagery inaccurate, since it says that imagery necessarily represents visual experience, yet there is a centrally important feature of visual experience that imagery does not characteristically reproduce.

How should weak perceptualists respond? I mentioned above how The Twofold Phenomenology of the Visual Field has been put to a number of explanatory uses. This means that its existence is not something that weak perceptualists are able to dismiss out of hand. More problematically, both Martin and Soteriou are themselves committed to its existence. Indeed, this relevant conception of a visual field was first developed by Martin (1992) as a way to potentially individuate vision and distinguish it from other spatial senses, like touch, another potential explanatory use. The notion of such a field has subsequently been developed by Soteriou as follows:

[W] hen looking straight ahead, any region of space in front of you that you are thereby aware of is presented as a $s u b$-region of a region of space that has that sub-region as part... [I]t may be said that you are visually aware of something like a cone of physical space in front of you, and we might think of the boundaries of this cone as the boundaries of your visual field. (2013, p.118)

Soteriou continues, explicating the extra-visual feature:

Rather than thinking of the boundaries of the visual field as boundaries of some thing one is sensing, we should think of the boundaries of the visual field in terms of one's sensory limitations. That there are limits to what can now be sensed that are due to one's sensory limitations... brings with it the idea that there is more to be sensed beyond those sensory limits, hence the idea that your visual awareness of the region of space in front of you is in some sense an awareness of the region as a sub-region of a region of space that has that subregion as part. That you visually experience a region of space in front of you in this way is an important part of the conscious character of visual experience. (p.118)

As Soteriou says, this is an important part of the phenomenal character of vision. Insofar as it seems absent in much, typical imagery experience, we should not think of mental imagery, as The Dependency Thesis does, as represented perceptual experience, lest we render virtually all imagery inaccurate. In ignoring such features, weak perceptualists work with an impoverished view of perceptual experience's structural features, and by their own lights. Thus, the view fails, overall, as an account of both projected and non-projected imagery. ${ }^{18}$

\footnotetext{
18 These claims about the failure of imagery to represent the extra-visual feature are very much in-tune with, and can perhaps throw light on, some of Jean-Paul Sartre's (1940/1972) more provocative remarks regarding the "essential poverty" (p.8) of imagery in relation to perception. Consider his claim that the objects of perception, but not the objects of imagery, 'overflow' conscious: "In a word, the object of the perception overflows consciousness constantly; the object of the image is never more than the consciousness one has of it; it is limited by that consciousness." (Ibid.).
} 


\section{Conclusion}

What is the relationship between perception and mental imagery? I have attempted here to eliminate one answer: perceptualism about mental imagery, in both strong and weak forms. This leaves open a number of alternatives, which I sketched at this paper's beginning. Crucially, none of this is to deny that there exist a multitude of properties shared between perception and imagery, whether that be shared neural correlates ${ }^{19}$ or a shared iconic format. ${ }^{20}$ Still, let this paper be a cautionary tale not to overestimate those similarities. Whatever the relationship between perception and imagery, the perceptualist has it wrong.

Acknowledgements Thanks to Margot Strohminger and colleagues at the Open University for comments on an earlier version. Thanks also to two of the journal's anonymous referees.

Open Access This article is licensed under a Creative Commons Attribution 4.0 International License, which permits use, sharing, adaptation, distribution and reproduction in any medium or format, as long as you give appropriate credit to the original author(s) and the source, provide a link to the Creative Commons licence, and indicate if changes were made. The images or other third party material in this article are included in the article's Creative Commons licence, unless indicated otherwise in a credit line to the material. If material is not included in the article's Creative Commons licence and your intended use is not permitted by statutory regulation or exceeds the permitted use, you will need to obtain permission directly from the copyright holder. To view a copy of this licence, visit http:// creativecommons.org/licenses/by/4.0/.

\section{References}

Aleman, A., de Haan, E., \& Kahn, R. (2005). Object versus spatial visual mental imagery in patients with schizophrenia. Journal of Psychiatry \& Neuroscience, 30, 53-56.

Allen, K. (2015). Hallucination and Imagination. Australasian Journal of Philosophy, 93, 287-302.

Andrade, J., May, J., \& Kavanagh, D. (2012). Sensory Imagery in craving: From cognitive psychology to new treatments for addiction. Journal of Experimental Psychopathology, 3, 127-145.

Bainbridge, W., Pounder, Z., Eardley, A., \& Baker, C. (2021). Quantifying aphantasia through drawing: Those without visual imagery show deficits in object but not spatial memory. Cortex, 135, 159-177.

Bartolomeo, P. (2002). The relationship between visual perception and visual mental imagery: A reappraisal of the neuropsychological evidence. Cortex, 38, 357-378.

Beck, J. (2018). Marking the perception-cognition boundary: the criterion of stimulus-dependence. Australasian Journal of Philosophy, 96, 319-334.

Briscoe, R. (2008). Vision, action and make-perceive. Mind \& Language, 23, 457-497.

\footnotetext{
19 Despite what many philosophers believe, the idea that perception and imagery share neural correlates is far from a settled matter. One reason for scepticism in the empirical literature is precisely the clinical findings reported in Sect. 3.2. As a recent meta-analysis of work on this area put it aphantasia in particular is "at odds with models [of imagery] proposing a crucial implication of early visual areas." (Spagna et al. 2021, p.202; see also Bainbridge et al. 2021) I take up these empirical matters, about aphantasia and the neural substrate of mental imagery, in greater detail elsewhere (Cavedon-Taylor forthcoming).

${ }^{20}$ In terms of perception and imagery sharing an iconic format, I take this to be undeniable. What is deniable is that iconicity is the mark of the perceptual, as opposed to purporting to represent particular objects in the here and now, a criterion on which imagery is non-perceptual (see Beck 2018 and Phillips 2019 for discussion). Mental imagery, like perception, can represent objects to be in the here and now; unlike perception, and like belief and desire, etc. it needn't do so of necessity.
} 
Brockmole, J., Wang, R., \& Irwin, D. (2002). Temporal integration between visual images and visual percepts. Journal of Experimental Psychology: Human Perception and Performance, 28, 315-334.

Brown, D. (2018). "Infusing Perception with Imagination." In F. Macpherson and F. Dorsch (eds.) Perceptual Memory and Perceptual Imagination. OUP.

Byrne, A. (2007). Possibility and imagination. Philosophical Perspectives, 21, 125-144.

Cavedon-Taylor, D. (2018). Sensorimotor expectations and the visual field. Synthese. Online first. https:// doi.org/10.1007/s11229-018-01946-4

Cavedon-Taylor, D. (forthcoming). "Untying the knot: Imagination, perception and their neural substrates." Synthese.

Clark, A. (2014). "Perceiving as Predicting." In D. Stokes, M. Matthen and S. Biggs (eds.) Perception and its Modalities. OUP.

Cocude, M., Charlot, V. \& Denis, M. (1997). "Latency and duration of visual mental images in normal and depressed subjects.” Journal of Mental Imagery: 127-142.

Crane, C., Shah, D., Barnhofer, T., \& Holmes, E. (2012). Suicidal imagery in a previously depressed community sample. Clinical Psychology \& Psychotherapy, 19, 57-69.

Currie, G. \& Ravenscroft, I. (2002). Recreative Minds. OUP.

Dawes, A., Keogh, R., Andrillon, T., \& Pearson, J. (2020). A cognitive profile of multi-sensory imagery, memory and dreaming in aphantasia. Scientific Reports, 10, 10022.

Dorsch, F. (2016). "Hume." In A. Kind (ed.) The Routledge Handbook of Philosophy of Imagination. Routledge.

Eddy, J. K., \& Glass, A. L. (1981). Reading and listening to high and low imagery sentences. Journal of Verbal Learning and Verbal Behavior, 20, 333-345.

Farah, M. J., Levine, D. N., \& Calvanio, R. (1988). A case study of mental imagery deficit. Brain and Cognition, 8, 147-164.

Firestone, C., \& Scholl, B. (2016). Cognition does not affect perception: evaluating the evidence for "topdown" effects. Behavioral and Brain Sciences, 39, 1-72.

French, C. (2018). Bálint's syndrome, object seeing, and spatial perception. Mind \& Language, 33, 221-241.

Goldman, A. (2006). Simulating Minds. OUP.

Gosselin, F., \& Schyns, P. (2003). Superstitious perceptions reveal properties of internal representations. Psychological Science, 14, 505-509.

Grush, R. (2004). The emulation theory of representation: motor control, imagery, and perception. Behavioral and Brain Sciences, 3, 377-396.

Hirsch, C., Clark, D., Matthews, D., \& Williams, R. (2003). Self-Images play a causal role in social phobia. Behaviour Research and Therapy, 41, 909-992.

Hobbes, T. (1651/1991). Leviathan. CUP.

Hoerl, C. (2018). Experience and time: Transparency and presence. Ergo, 5, 127-151.

Hohwy, J. (2013). The Predictive Brain. OUP.

Holmes, E., Geddes, J., Colom, F., \& Goodwin, G. (2008). Mental Imagery as an emotional amplifier: Application to Bipolar Disorder. Behaviour Research and Therapy, 46, 1251-1258.

Hume, D. (1739). A Treatise of Human Nature. Oxfoerd University Press.

Ivins, A., Di Simplicio, M., Close, H., Goodwin, G., \& Holmes, E. (2014). Mental imagery in bipolar affective disorder versus unipolar depression: investigating cognitions at times of 'positive' mood. Journal of Affective Disorders, 166, 234-242.

Kang, S., Sponheim, S., Chafee, M., \& MacDonald, A. (2011). Disrupted functional connectivity for controlled visual processing as a basis for impaired spatial working memory in Schizophrenia. Neuropsychologia, 49, 2836-2847.

Keogh, R., \& Pearson, J. (2018). The blind mind: No sensory visual imagery in aphantasia. Cortex, 105, 53-68.

Kind, A. (2018). Imaginative Presence. In F. Dorsch, F. Macpherson, \& M. Nide-Rumelin (Eds.), Perceptual Presence. OUP.

Kirchhoff, M. (2018). Predictive processing, perceiving and imagining: is to perceive to imagine, or something close to it? Philosophical Studies, 175, 751-767.

Kosslyn, S. (1994). Image and Brain. MIT Press.

Kosslyn, S., Behrmann, M., \& Jeannerod, M. (1995). The cognitive neuroscience of mental imagery. Neuropsychologia, 33, 1335-1344.

Kosslyn, S., Thompson, W., \& Ganis., W. (2006) The Case for Mental Imagery. Oxford University Press. 
Laeng, B., Bloem, I., D’Ascenzo, S., \& Tommasi, L. (2014). Scrutinizing visual images: The role of gaze in mental imagery and memory. Cognition, 131, 263-283.

Langland-Hassan, P. (2015). Imaginative attitudes. Philosophy and Phenomenological Research, 90, $665-686$.

Liao, S-Y. \& Gendler, T. (2019). "Imagination.” In E. Zalta (ed.) Stanford Encyclopedia of Philosophy. URL = https://plato.stanford.edu/archives/win2019/entries/imagination/

Lormand, E. (2006). Phenomenal Impressions. In T. Gendler \& J. Hawthorne (Eds.), Perceptual Experience. Oxford University Press.

Macpherson, F. (2012). Cognitive penetration of colour experience: Rethinking the issue in light of an indirect mechanism. Philosophy and Phenomenological Research, 84, 24-62.

Martin, M. G. F. (1992). Sight and Touch. In T. Crane (Ed.), The Contents of Experience. Cambridge University Press.

Martin, M. G. F. (2002). The Transparency of experience. Mind \& Language, 17, 376-425.

McGill, B., \& Moulds, M. (2014). Characteristics of autobiographical memories and prospective imagery across a spectrum of hypomanic personality traits. Memory, 22, 1139-1148.

Moro, V., Berlucchi, G., Lerch, J., Tomaiuolo, F., \& Aglioti, S. (2008). Selective deficit of mental visual imagery with intact primary visual cortex and visual perception. Cortex, 44, 109-118.

Nanay, B. (2010). Perception and imagination: Amodal perception as mental imagery. Philosophical Studies, 150, 239-254.

Nanay, B. (2015). Perceptual content and the content of mental imagery. Philosophical Studies, 172, $1723-1736$.

Nanay, B. (2016). Hallucination as mental imagery. Journal of Consciousness Studies, 23, 65-81.

Nanay, B. (2017). Pain and mental imagery. The Monist, 100, 485-500.

Nanay, B. (2018). Multimodal mental imagery. Cortex, 105, 125-134.

Nanay, B. (2020). Multimodal Mental Imagery and Perceptual Justification. In D. Gatzia \& B. Brogaard (Eds.), The Epistemology of Non-Visual Perception. OUP.

Nanay, B. (2021). Unconscious mental imagery. Philosophical Transactions of the Royal Society B, 376, 20190689.

Nanay, B. (forthcoming). Mental Imagery. OUP.

Oertel, V., Rotarska-Jagiela, A., van de Ven, V., Haenschel, C., Grube, M., \& Stangier, U. (2009). Mental imagery vividness as a trait marker across the schizophrenia spectrum. Psychiatry Research, 167, $1-11$.

Peacocke, C. (1985). "Imagination, experience, and possibility.” In J. Foster \& H. Robinson (eds.) Essays on Berkeley. OUP.

Peacocke, C. (1992). A Study of Concepts. MIT Press.

Pearson, D., Deeprose, C., Wallace-Hadrill, D., Heyes, D., \& Holmes, E. (2013). Assessing mental imagery in clinical psychology: A review of imagery measures and a guiding framework. Clinical Psychology Review, 33, 1-23.

Pearson, J., Naselaris, T., Holmes, E., \& Kosslyn, S. (2015). Mental imagery: Functional mechanisms and clinical applications. Trends in Cognitive Science, 19, 590-602.

Phillips, B. (2019). The shifting border between perception and cognition. Nous, 53, 316-346.

Pylyzhyn, Z. (1999). Is Vision continuous with cognition? Behavioral and Brain Sciences, 22, 341-423.

Richardson, L. (2010). Seeing empty space. European Journal of Philosophy, 18, 227-243.

Richardson, L. (2014). Space, time and molyneux's question. Ratio, 27, 483-505.

Sartre, J-P. (1940/1972) The Psychology of the Imagination. Routledge.

Segal, S. (1972). Assimilation of a Stimulus in the Construction of an Image: The Perky Effect Revisited. In P. Sheehan (Ed.), The Function and Nature of Imagery. Academic Press.

Sellars, W. (1978). The role of Imagination in Kant's Theory of Perception. In H. Johnstone (Ed.), Categories: A Colloquium. Penn State University Press.

Shepard, R. (1978). Mental images. American Psychologist, 33, 125-137.

Siegel, A., \& Silins, N. (2015). The Epistemology of Perception. In M. Matthen (Ed.), Oxford Handbook to the Philosophy of Perception. OUP.

Soteriou, M. (2013). The Mind's Construction. Oxford University Press.

Smith, J. (2006). Bodily awareness, imagination and the self. European Journal of Philosophy, 14, 49-68.

Spagna, A., Hajhajate, D., Liu, J., \& Bartolomeo, P. (2021). Visual mental imagery engages the left fusiform gyrus, but not the early visual cortex: A meta-analysis of neuroimaging evidence. Neuroscience \& Biobehavioral Reviews, 122, 201-217. 
Thomas, A. (2009). Perceptual presence and the productive imagination. Philosophical Topics, 37, 153-174.

Van Leeuwen, N. (2011). Imagination is where the action Is. Journal of Philosophy, 108, 55-77.

Whiteley, C. M. (2020). Aphantasia, imagination and dreaming. Philosophical Studies, 44, 1-22.

Williams, J., Ellis, N., Tyers, C., Healy, H., Rose, G., \& MacLeod, A. (1996). The specificity of autobiographical memory and imageability of the future. Memory \& Cognition, 24, 116-125.

Wiltsher, N. (2016). Against the additive view of the imagination. Australasian Journal of Philosophy, 94, 266-282.

Winlove, C., Milton, F., Ranson, R., Fulford, J., MacKisack, M., Macpherson, F., \& Zeman, A. (2018). The neural correlates of visual imagery: A co-ordinate-based meta-analysis. Cortex, 105, 4-25.

Young, B. (2020). Olfactory imagery: Is exactly what it smells like. Philosophical Studies, 177, 3303-3327.

Zeman, A., Dewar, M., \& Della Sala, S. (2015). Lives without imagery: Congenital aphantasia. Cortex, 73, 378-380.

Zeman, A., Milton, F., Della Sala, S., Dewar, M., Frayling, T., Gaddum, J., Hattersley, A., HeuermanWilliamson, B., Jones, K., MacKisack, M., \& Winlove, C. (2020). Phantasia-the psychological significance of lifelong visual imagery vividness extremes. Cortex, 130, 426-440.

Publisher's Note Springer Nature remains neutral with regard to jurisdictional claims in published maps and institutional affiliations. 